\title{
SISTEMA y Creación de Necesidades: Evolución y Aplicación de los Derechos Humanos*
}

\author{
Por: Alexander Herrera** y Ricardo Landínez ${ }^{* * *}$
}

\section{Resumen}

El artículo trata de las dimensiones del desarrollo humano y las formas de reproducción de lo social. Busca hacer evidente la necesidad de interpretar la relatividad del desarrollo y su relación con los contextos sociales, políticos y económicos bajo los cuales se desenvuelve la civilización y que día a día tienden cada vez más a generar consecuencias negativas para el planeta y para el mismo ser humano. El texto llama a reconsiderar el papel transformador del Ser Humano como sujeto activo y su vinculación con el ejercicio de sus derechos en una práctica de libertad.

\section{Palabras Claves}

Necesidades, Derechos Humanos, Desarrollo Humano, Libertad.

\begin{abstract}
This article discusses some dimensions of human development and forms of social breeding. Development is to be interpreted as contingent to social, political and economic factors under which civilization takes place. Its negative effects may gradually jeopardize people's welfare and that of the entire planet. The article also calls for a reconsideration of the transforming role of human beings as active subjects and their exercise of their rights in freedom.
\end{abstract}

\section{Key Words}

Needs, Human Rights, Human Development, Freedom

*** Ricardo Landínez es Economista, profesor de la Facultad de Ciencias Empresariales en UNIMINUTO.

Artículo:

Recibido, 16 de noviembre de 2006; aprobado, 28 de febrero de 2007

\footnotetext{
* Este texto ha sido elaborado en el marco de las discusiones adelantadas en el Centro de Investigaciones Humanas y Sociales CEIHS- para efectos la investigación sobre desarrollo humano y Social.
} 


\section{INTRODUCCIÓN}

Sobre desarrollo se ha dicho mucho desde que, como concepto, entró a hacer parte de la academia y de la agenda de discusión política tanto de los Estados como de los organismos multilaterales. El concepto toma fuerza a partir del final de la II guerra mundial, especialmente en relación con los países más empobrecidos y basaba sus índices de medición en bienes y servicios relacionados por consumos entre los países ricos y los países pobres. La visión economicista del concepto empezó a sufrir cambios positivos a partir del año 1975 en el que se incluye una visión multidimensional de la sostenibilidad, argumentando que: "la noción de que lo mayores factores limitantes para los logros humanos son socio-políticos, institucionales y de comportamiento, no excluye que hay límites biológicos y físicos externos, más allá de los cuales el hombre no debe ir si pretende preservar la integridad de la capacidad de carga de los ecosistemas" ${ }^{\prime \prime}$. Nuevas preguntas surgen a partir del posicionamiento de esta concepción que implican el desarrollo visto desde ámbitos culturales, regionales, multiculturales, económicos y de bienestar.

En primera instancia, desde la mirada de análisis político que adelantamos, resulta fácil aceptar que el Estado es, si no el único, si uno de los principales actores a la hora de pensar el desarrollo. Constituido para hacer respetar la interdicción del uso de la violencia particular y garantizar la seguridad general, el Estado es, siguiendo la tradición liberal: "El único modo de erigir un poder común que pueda defenderlos de la invasión de extraños y de las injurias entre ellos mismos, dándoles seguridad que les permita alimentarse con el fruto de su trabajo y con los productos de la tierra y llevar así una vida satisfecha, es el de conferir todo su poder y toda su fuerza individuales a un solo hombre o a una asamblea de hombres, que mediante la pluralidad de votos, puedan reducir las voluntades de los súbditos a una sola voluntad." Supone esta concepción el monopolio de la fuerza al mismo tiempo que cimientos sólidos de democracia.

Pero la tradición liberal tuvo su evolución con el paso del tiempo; las limitaciones y la separación de poderes se hicieron necesarias, al igual que la aceptación universal del derecho a la desobediencia civil y a los cambios en la teoría de los derechos naturales. Especialmente a partir de 1945 el derecho que nace, (entendido como avance del concepto de desarrollo que vincula diferentes esferas de la sociedad humana) incorpora la teoría de los Derechos humanos como mecanismo de defensa de los ciudadanos ante las exacerbaciones del Estado ${ }^{3}$; exacerbaciones que le valieron a este último críticas tanto en su espíritu como en su accionar. Desde el marxismo, el Estado representa el interés de la clase dominante, otros como Ostrogorski lo aíslan de su rol político dejando esta ocupación a la sociedad civil pero atribuyéndole su función ejecutiva y legislativa sin dejar de reconocer igualmente el Estado como poder de un cierto monopolio de clase. Para Michels el problema de la racionalidad del Estado reside en el problema del mantenimiento de la democracia, en tanto oligarquía (quien dice organización, dice oligarquía) el Estado adolece del problema de la concentración del poder. Michels considera que la plebe es fácilmente influenciable, demasiado numerosa para organizarse ágilmente y por tanto incapaz de gobernarse a sí misma, ella deberá acudir necesariamente a la adopción de un sistema de representación: la democracia. En suma todos estos enfoques teóricos reconocen los peligros de la concentración de poder en el Estado y sugieren una consecuente necesidad de establecimiento de garantías ciudadanas manifestadas en derechos, sólo posibles en un sistema de democracia.

Fue así como, luego de la Segunda Guerra Mundial el fortalecimiento de la interacción de los Estados implicó la creación de un sistema

1. La Gollina de los Huevos de Oro. Debate Sobre el Concepto de Desarrollo Sostenible. Wolfgang Sachs. Http://www.redescolusa.org/pdf/desc/economicos/sostenible sostenible.pdf

2. Hobbes, Thomas. Levialán. Grandes Obras del Pensamiento. Ed. Altaza. 2000 Pág. 144

3. "Le droit qui naît après 1945 est fondamentalement différent. Il entend appréhender l'individu ses droits, sa sécurité, en dehors de tout lien d'appartenance avec un Élat ». Au-delà de l'État. Le Droit international et la défense des droits de l'homme. Amnesty International. 1992 Pág. 26 
moderno de relaciones internacionales que en parte reconocía la necesidad de proteger al ciudadano del organismo Estatal. Esta relación significó una nueva mirada de cara al papel del Estado frente a la generación de la ciudadanía y de reconocimiento del sujeto como actor social. Siendo la ciudadanía la fuente del vínculo social, ser ciudadano significa entonces ser sujeto de derecho y de deberes. En tanto que el poder ${ }^{4}$ de los Estados reside en la legitimidad política, el ciudadano como participe del Estado- es el verdadero portador de una parte fraccionada de soberanía política. La idea de derecho ciudadanoevoluciona entonces en el camino de la limitación de la acción represiva y exacerbada del Estado.

Bajo esta mirada, respecto del rol del Estado y del reconocimiento de los derechos, el desarrollo humano y social se plantea como una totalidad que recoge la acción política en la legitimidad de la acción estatal, de su representación colectiva y del uso de la fuerza, junto con un mayor reconocimiento del ciudadano como sujeto político y parte beneficiaria de derecho. En este orden de ideas, las concepciones de libertad, participación e igualdad se ven reformuladas y planteadas desde la evolución del derecho jurídico. Aunque esto no se dé de manera generalizada en el conjunto de los bloques políticos regionales (Asía, Europa, Norte América, América Latina y África), la sociedad global plantea una serie de instrumentos jurídicos internacionales con pretensión universal en la vía de garantizar valores morales y políticos deseables desde la lógica occidental y resumidos en la concepción integral de los Derechos Humanos.

El vínculo entre Derechos y Estado, y para nuestro caso, dentro del marco de desarrollo, se encuentra en el nudo jurídico fundamental del concepto de ciudadanía. Emanado de la invención de la ciudad griega y reforzada en su concepción por el civis romanus, de donde se deriva su vocación universal, en el concepto de ciudadanía se establece la igualdad en derecho.

La igualdad en derecho nos significa la posibilidad, nominal y efectiva, de la participación del ciudadano. Esta participación nos refiere a la generalidad de la acción humana en cuanto al legítimo derecho de acceso a recursos para su desarrollo particular y colectivo de la libertad como categoría no restringida sino por la limitante que demandan los derechos de otros. ${ }^{5}$. Ciudadanía y libertad se encuentran íntimamente ligados, puesto que la una no puede ser sin la otra y viceversa. Siguiendo a Sen, el compromiso de las garantías de la libertad se conjuga no sólo en el seno del Estado, sino que se hace posible mediante la exigencia y defensa activa de la participación ciudadana: "La sociedad no tiene por qué comprometerse a defender la libertad individual sólo a través del Estado, sino también a través de otras instituciones, las organizaciones políticas $y$ sociales, ciudadanas, ong ${ }^{\prime \prime 6}$

En suma, la libertad, siendo el fin primordial y el medio principal del desarrollo (Sen: 2000; 54 75) vincula Estado y derecho en una síntesis en la que existen fuertes tensiones a la hora de concebir el desarrollo. Dada la naturaleza violenta del Estado, la existencia de los derechos humanos como norma jurídica, es finalmente un cambio importante y trascendental en la evolución del Estado-nación y en relación con su concepción originaria (si bien no mucho en relación a su esencia natural). Los avances en materia de derechos y de la comprensión vital respecto de la intervención de la sociedad civil en la esfera de acción del Estado están ligados con la noción o las nociones de desarrollo que las sociedades se forman; es decir es en esencia e igualmente relativa.

4. Nos referimos aquí a poder en términos de abstracción y no al poder efectivo o reaccionario de los Estados dictatoriales, los que, utilizando la violencia conservadora no hacen uso de una fuente de legitimidad en la democracia, sino de las armas y coerción física. Como lo sostiene Benjamín: "Si la justicia es el criterio de los fines, la legitimidad lo es el de los medios" Benjamín Para una crítica de la violencia y otros ensayos. Iluminaciones IV Taurus Humanidades. Madrid. 1991 Pág. 24

5. "La Liberté consiste à pouvoir faire lout ce qui ne nuit pas à autrui : ainsi, l'exercice des droits naturels de chaque homme n'a des bornes que celle qui assurent aux autres membres de la société la jouissance de ces mêmes droits " Articulo 4 de la Declaración francesa de los derechos del hombre y del ciudadano. 1789 


\section{SISTEMA Y CREACIÓN DE NECESIDADES}

Cuando decimos que la noción de desarrollo pertenece a una categoría relativa nos referimos al hecho de la existencia de factores marcados por contextos específicos de pretensiones universalistas. La noción de desarrollo no es la misma en todas las geografías, ni atravesada por los mismos valores sociales. De hecho, el avance en los desarrollos jurídicos de la concepción universal de los derechos humanos vio sus tropiezos en la concepción occidental de cara a normas y valores venidos especialmente de oriente y del mundo árabe. Las tres críticas más recurrentes establecidas por Sen en su obra: Desarrollo y libertad, se refieren al problema que se establece en la legitimidad del cuerpo teórico de los derechos humanos, en la coherencia del mismo en tanto no existen necesariamente las instituciones que garanticen su efectividad y por último, en la crítica cultural que hace referencia a la capacidad de universalización de los Derechos Humanos. Poniendo así de manifiesto, la relatividad de la libertad, la tolerancia y la igualdad respecto de las diferentes culturas.

Pero entonces, źqué es lo que hace que exista tal relatividad? Mucho se podría decir de la influencia de valores tradicionalmente enraizados en las comunidades y las naciones. El hecho de que el mundo musulmán no contemple ciertos derechos de las mujeres como componente necesario para el alcance del desarrollo a pesar de que es comúnmente reconocido que la participación y productividad de las mujeres aporta sustancialmente a la generación de la riqueza, es diciente.

Podemos entonces aventurarnos a establecer que el nudo conceptual del problema de la relatividad del desarrollo está determinado por la concepción que del concepto de necesidad tenemos. Es con Spinoza (1632-1677) que occidente empieza a teorizar seriamente dicho concepto. Siguiendo a Descartes, Spinoza recoge el hecho de la existencia de una necesidad real y otra pensada, supuesta. La necesidad real plantea la esencia pura de las cosas, su naturaleza intrínseca; mientras que la necesidad pensada representa la racionalidad del discurso. La necesidad es entonces "libertad" para decidir eso que se necesita o que se desea.

Es con el advenimiento del mundo moderno y en específico, con la actividad del mundo de información global, que la noción de necesidad cobra un carácter universalmente impositivo. Necesidad y deseo convergen simultáneamente para auto procrearse cuando el mundo tecnológico moderno genera pautas universales de concepción de la vida y de la sociedad. No es un azar el que los consumos de bienes culturales y materiales presenten sentidos homogéneos independientemente de los contextos en que el sujeto actúe. Pero, żen dónde radica la contradicción? En los manuscritos del 44 Marx nos esclarece respecto del problema de la necesidad; diferenciando entre necesidades naturales y necesidades socialmente determinadas, siendo las primeras naturales y las segundas digamos, ficticias. En todo caso unas y otras están vinculadas, en primera instancia, con la producción de la materia $y$, en segunda instancia, con la producción de la mercancía: "EI hombre produce incluso libre de la necesidad física y sólo produce realmente liberado de ella"'?

La necesidad socialmente determinada tiene intrínseca la mercancía como objeto social de consumo. El aspecto problemático, referido a la concepción del desarrollo, radica en que existen necesidades creadas por los medios de comunicación y en general por la dinámica social que justifican ciertos consumos de mercancías culturales y materiales producidas a partir de un modo de producción socio-económico que riñe con el ideal del valor de la humanidad. La contradicción reside en la atomización del sujeto que deviene individuo desvinculado de su colectivo de referencia en tanto que, si hablamos de humanidad, habrá entonces que llenar el concepto de contenido: que realice la unidad de lo necesitado y deseado al mismo tiempo que la

6. Sen, Amartya. Desarrollo Y Libertad. Traducción de Esther Tabasco y Luis Toharia. Editorial Planeta. Barcelona, España. 2000. Póg. 340

7. Marx, Carlos. Manuscritos de Economía y Filosofía. Ed. Alianza, Madrid. 1969 Pág. 112 
realización de lo necesitado y deseado de la unidad $^{8}$.

La necesidad o el deseo práctico modifica el concepto de desarrollo que el sujeto ${ }^{9}$ del mundo moderno vive. Bien entendido, el mundo moderno se ha alejado de las necesidades naturales en su natural evolución; ha desarrollado un sentido social determinado por nuevos valores (y en muchos casos antivalores) que vinculan una relación diferente de la materia básica de sobrevivencia en el que el lujo ${ }^{10}$ y el confort se convierten en una búsqueda frustrada para la mayoría de los pobladores del planeta. El problema no es en sí la materia como existencia pura, sino el sentido particularista que se imprime (en el mundo mercantil) en cada uno de los sujetos desvinculándolos de su responsabilidad frente a los otros y frente al mundo natural que le rodea. Lo que está en juego es, en consecuencia, el vaciamiento de sentido de la responsabilidad que atañe a uno y otro ser humano; es la sustitución arbitraria de las necesidades naturales por las necesidades socialmente determinadas".

Si la necesidad social creada determina el modus vivendi de los sujetos en sociedad, la noción de cambio y evolución, en suma, de desarrollo, está determinada por condiciones generales y particulares provenidas de los contextos, de la evolución del entramado social que en cada uno se genera y de los intercambios interculturales que los grupos humanos (nación, comunidad, grupo, etc.) sostienen. Esto significa que la noción de desarrollo no puede ser homogénea y que depende de la manera como cada una de las sociedades asume e incorpora los cambios tecnológicos, los valores y la información que en ella fluye. Sin embargo, ciertas nociones de desarrollo tienden a buscar una fuerza para volverse y ser universales, estableciendo pautas globales mediante el consumo material y cultural en abierta pugna con valores contradictorios Nerbigracia: el mundo árabe musulmán y occidente). La lucha se establece en los repertorios cargados de sentidos y de valores que caracterizan la identidad de cada uno de los colectivos, por lo que la noción de desarrollo se reinterpreta en un entramado de valores determinados por las necesidades ubicadas en contextos y espacios definidos.

Las condiciones generales y particulares que producen y reproducen el modus vivendi son a su vez producidas y reproducidas por el modus vivendi; es en resultado una dialéctica de la conservación. Aquí reside el papel de la ideología y de la reproducción de la ideología: "es evidente, un hecho empírico el que los individuos concretos, al extenderse sus actividades hasta un plano histórico universal, se ven cada vez más sojuzgados bajo un poder cada vez más extraño a ellos (cuya opresión llega luego a considerar como una perfidia del llamado espíritu universal, etc.), poder que adquiere un carácter cada vez más de masa y se revela en última instancia como el mercado mundial ${ }^{\prime 12}$ La ideología sustenta y crea la necesidad y el sujeto se ve cada vez más influenciado por una forma particular y universal de ver e interpretar el mundo.

Por ello, una de las dimensiones que comporta y desde la cual también se constituye el ser y hacer del hombre, es la económica. Se debe

8. "Mais est-elle vraiment ? Peut-on parler d'une humanité? Sans doute, il est toujours possible de donner un nom collectif à Pensemble des hommes, mais ce sera en les considérants du dehors, comme des objets unifiés par lespace qu'ils remplissent; cette collectivité ne sera qu'un troupeau d'animaux intelligents; nous n'avons rien à faire avec ce donné figé dans la plénitude de son être. Pour que nous puissions agir pour l'humanité il faut qu'elle réclame quelque chose de nous; il fut qu'elle possède une unité en tant que totalité qui cherche à se réaliser, et qu'elle nous appelle d'une seule voix „Beauvoir, Simone de. Pour une morale de l'ambiguilié. Folio essais. Ed. Gallimard, 1947. Pág. 238

9. Aquí hablamos de sujeto y no de ciudadano en tanto que la realización de la ciudadanía no es un logro universal en todas las naciones y aún se encuentra en ciernes de cara a la noción moderna de ciudadano.

10. Entendido como antitesis de lo naturalmente necesario. Marx. Elementos fundamentales par la crítica de la Económica política. Ed. Siglo XXI. Madrid. 1972 Vol. I pp. 266-267 Citado por Heller Àgnes. Teoría de las Necesidades en Marx. Ediciones Península. Barcelona 1978. Pág. 31

11. "En su aspiración incesante por la forma universal de la riqueza, el capital, empero, impulsa el trabajo más allá de los límites de su necesidad natural y crea así los elementos materiales para el desarrollo de la rica individualidad, fan multilateral en su producción como en su consumo, y cuyo trabajo por ende, tampoco se presenta ya como trabajo, sino como desarrollo pleno de la actividad misma, en la cual ha desaparecido la necesidad natural en su forma directo, por que una necesidad producida históricamente, ha sustituido a la natural" lbíd. 
comprender esta dimensión como la necesaria actuación e interrelación de hombres y mujeres para producir su vida material, la realización de formas de producción en sociedad que deberían permitir un esencial mejoramiento de las condiciones de vida material y social en derecho (vivienda, salud, recreación).

En la producción económica se podrían hacer dos consideraciones relacionadas entre sí. La primera hace referencia al hecho de que la producción material de la existencia determina el modo de vida de los individuos. Las representaciones mentales de estos, su conciencia, son producto de la forma como producen las mercancías (Marx) y, a su vez, esta producción material reproduce el mundo de las relaciones necesarias para producir bienes materiales y simbólicos que dan sustento material y espiritual a su existencia. No obstante, las críticas a la teoría Marxista, plantean lo humano en su esencia multidimensional que pasan por esferas de lo social que van más allá de las formas de producción dominantes. Castoriadis, por ejemplo, plantea que la Psique, entendida como la imaginación radical del ser humano, no se puede reducir a unos comportamientos reflejos de lo social, sino que desde aquella hay pistas para entender la construcción de lo social humano. La psique construye su mundo independiente del mundo social y desde aquí deriva su teoría central de la imaginación radical, no condicionada siempre por el entorno social y desde donde podría entenderse asimismo el desarrollo de las sociedades y los individuos.

Desde esta perspectiva, lo económico en su dimensión de actividad producida por los seres humanos, vida productiva de hombres y mujeres, es la continua creación y recreación de formas y actividades para procurar satisfacer necesidades naturales y sociales, en las que están inmersas creencias, tradiciones, pero también potencialidades y capacidades. Es decir, la producción en sociedad (o en comunidad), no es producto de un mero acto instintivo de supervivencia, es también la continua expresión y creación de sentidos, de formas de producir y consumir bienes materiales y culturales. El atraso en que viven muchos grupos humanos, expresadas en formas precarias de producción y de consumo, determinan también una precaria movilidad social y por tanto, vínculos con formas de organización económicas sociales no adecuadas de acuerdo a la lógica occidental y que no suscitan la participación, tampoco el pleno ejercicio de derechos $y$, en concordancia con Sen, la plena expresión de su libertad puesta en contexto y desarrollada a voluntad ${ }^{13}$. ¿̇Existirá entonces una pobreza de imaginación para la creación de nuevos órdenes sociales?

En el dominio de la economía, ha tenido peso la llamada escuela neoclásica cuya idea de un individuo humano absolutamente racional en realidad es una abstracción utilitarista basada en las decisiones que el individuo "libremente" escoge; pero en realidad se está obviando la influencia del entorno social, de las oportunidades $\mathrm{e}$ instituciones que posibilitan individuos con similares condiciones y capacidades. Es un enfoque, como plantea Sen, basado en el bienestar que sólo valora las situaciones en función de las utilidades que generan. En consecuencia aspectos de la calidad de vida como los derechos, la libertad individual, el reconocimiento, se excluyen.

Así, se encuentra la segunda consideración: los relatos y categorías que occidente propone tales como progreso, expansión o crecimiento, no son suficientes para dar cuenta de la situación de la sociedad y en especial de las comunidades más pobres. En su evolución, el capitalismo ha generado un sistema que no es tolerable para los humanos que lo componen: desempleo, especulación, hambre (Lyotard).

12. Marx, Carlos y Federico Engels. La ideología alemana. Ed. Andreus 1979. Pag. 34

13. "Une des principales objections que l'on adresse à l'existentialisme, c'est que le précepte : vouloir la liberté n'est qu'une formule creuse et ne propose aucun contenu concret à l'action. Mais c'est qu'on a commencé par vider le mot liberté de son sens concret; nous avons vu déjà que la liberté ne se réalise qu'en s'engageant dans le monde : si bien que son projet vers la liberté s'incarne pour l'homme dans des coduites définies " Beauvoir. Op. cit. Pág. 98 
El planeta se convierte entonces en un lugar propicio para la desigualdad e inequidad producto de un sistema que se ve en la obligación de reacomodar permanentemente la promesa de "universalidad" y "duración" no cumplida. Así, a la medición cuantitativa del crecimiento se le complementa una categoría más "cualitativa" el desarrollo. Pero el desarrollo que propone occidente, sólo quiere significar la capacidad de crecer materialmente sin fin. Es ideología y, a un nivel más profundo, significaciones imaginarias sociales. Consustancial a esa idea del desarrollo, existen unos postulados (teóricos y prácticos) que la soportan (Castoriadis): la omnipotencia virtual de la técnica, la ilusión relativa al conocimiento científico, la racionalidad de los mecanismos económicos, lemas que sustentan la idea de que el hombre y la sociedad están "naturalmente" predestinados al crecimiento y al progreso. Tienen cabida aquí, conceptos e ideas tales como el homus economicus, la mano invisible, liberalismo y virtudes de libre concurrencia ${ }^{14}$.

Si los hombres no sólo producen mercancías sino que reproducen sus propias representaciones condicionados por la forma en que están ubicados dentro de ese proceso de producción o mejor, condicionados por el desarrollo de las fuerzas productivas hay dos maneras de comprender la producción por la reproducción del capital y de la ideología. Pero, más allá de esto, también pueden ser creadores de nuevos órdenes sociales, gracias a su imaginación radical, que puede llevarlos a la creación y/o innovación de nuevas prácticas de producción de bienes y servicios y a una distribución más justa del excedente social y material producido.

En conclusión, la sociedad y las personas también crean o recrean formas de estar, producto de sus condiciones de vida materiales y de producción. Las formas de cooperación que se dan casi siempre resultan antagónicas en la medida que la propiedad privada, genera complejas redes de colaboración hacia un mismo fin desde la perspectiva del bien o servicio a producir, pero no desde la perspectiva de la distribución del excedente. En vía contraria, suceden también formas de cooperaciones en la vida urbana a partir de formas de producción solidarias; son generadoras de una economía social y de redes de apoyo o proximidad (economía popular, circuitos económicos, comercio con justicia). Emergen entonces nuevas relaciones sociales.

Estas prácticas productivas, en particular entendidas desde lo local, pero articuladas con los niveles regionales, nacionales o internacionales, deben mostrar entonces una dimensión de necesidades absolutamente nuevas que, como se ha mencionado, supone nuevas formas de producir y cambios absolutos en las prácticas culturales de consumo. Es decir, la asunción de otra lógica en las que el imaginario colectivo toma por cierto que el consumo desaforado e indiscriminado de todos los bienes materiales y culturales que ofrece el mercado, equivale a la satisfacción de necesidades, lo que conduce a una falsa idea de bienestar o calidad de vida. Por el contrario, pensamos que "Las necesidades humanas fundamentales son finitas, pocas y clasificables... son las mismas en todas las culturas y en todos los periodos históricos. Lo que cambia, a través del tiempo y de las culturas, es la manera o los medios utilizados para la satisfacción de las necesidades."15

\section{EVOLUCIÓN Y APLICACIÓN DE LOS DERECHOS, UNA PERSPECTIVA DEL DESARROLLO}

Anteriormente hemos enunciado la relación entre desarrollo y libertad entendida como parte fundamental de los derechos humanos. En tanto que la parte no es el todo, el desarrollo en relación con los derechos nos significa un sistema en el que se conjugan los presupuestos de libertad, dignidad e igualdad en derecho como pilar de la fundamentación teórica del sistema

14. También son consustanciales a esła idea, los conceptos de ingeniería humana e ingeniería social: organización y planificación burocráticas como soluciones universales aplicables a todo problema. Castoriadis "Reflexiones sobre el desarrollo y la racionalidad" en "El mito del desarrollo". Editorial Kairós 1980

15. Max-Neef. M, Elizalde.A, Hopenhayn.M. "Desarrollo a escala humana Una opción para el futuro" Uppsala: Cepaur, Fundación Dag. Hammarskjold. 1999. 
internacional de derechos humanos.

La noción de los Derechos Humanos surge como paradigma de solución en un contexto de posguerra y de reacomodamiento del orden mundial basado en principios e intencionalidades buenos. Se trata en suma de cómo la sociedad se organiza en ejercicio de su poder y de cómo regular la acción del Estado en términos de programas y de propósitos que vinculen cada vez más la noción práctica de ejercicio de ciudadanía. De la racionalidad económica se deriva el hecho preponderante de que los derechos conservan cono núcleo determinante la noción de progreso y no necesariamente la de la dignidad humana, fundamento base para el desarrollo de la teoría de los derechos humanos. Desde la lógica de la teoría del sistema internacional, el centro del planteamiento de dicha teoría se basa en la búsqueda del equilibrio del poder político de los Estados.

Así, la crítica al concepto de desarrollo se centra en la práctica del ejercicio de derecho de los ciudadanos. Por ejemplo, en la obra de Amartya Sen, "Desarrollo y Libertad", el autor nos argumenta dentro de las principales fuentes de privación de libertad; la pobreza y la tiranía. Su núcleo teórico establece las categorías de evaluación en función del aumento de las libertades de los individuos y la eficacia en donde el desarrollo depende totalmente de la libre agencia de los mismos.

La concepción moderna de derechos humanos se encuentra cuestionada en el alcance de su carácter universal tanto como en sus fundamentos epistemológicos ${ }^{16}$. Si bien en occidente el discurso de los Derechos Humanos es asumido con un cierto valor moral que logra modificar algunos escenarios incluso en el ámbito jurídico y en las pautas de comportamiento aún de los gobernantes más recalcitrantes; en oriente y en el mundo árabe el discurso de los derechos humanos es visto como una excusa para la dominación cultural que pretende ejercer occidente.

La relación entre la noción de desarrollo y derechos adolece del mismo problema que es inmanente a cada una de estas categorías: su deseo de universalidad y generalidad. Para Sen no puede haber desarrollo sin reconocimiento de derechos, no obstante ello es posible en el plano local en donde puede ser fácil de establecer, si se logra contrarrestar la energía, por naturaleza, violenta de los poderes locales; y sin embargo, desarrollo y derechos no son homogéneos en una posible interpretación universal. Como nos lo dice M. Yacoub: "L'occident pense néanmoins que ce qui est bon pour lui est naturellement bon pour l'humanité, d'où son universalisme abstrait et moralisant qui est, du reste, un trait marquant de son identité...mais aucune culture ne peut prétendre à elle seule incarner la raison universelle comme semble le faire la culture occidentale $~_{17}^{17}$

Ahora bien, dejando de lado el problema sustancial de la concepción de desarrollo y de derechos de pretensión universalista; podemos pensar que desarrollo y derechos están profundamente ligados por cuanto consideramos acertada la idea de que no es posible lograr el desarrollo $\sin$ un aumento de las libertades individuales, es decir, sin un aumento en derechos individuales. A ese respecto el premio Nóbel argumenta:

"La libertad individual es esencialmente un producto social, y existe una relación de doble sentido entre 1) los mecanismos sociales para

16. "En essayant d'interroger le concept diuniversalité des droits de thomme, on constante que, d'un point de vue philosophique, anthropologique et historique, il est limité. Pour l'expliquer, voici quelques observations méthodologiques sur l'expression droits de lhomme-, sur leur universalité et leur variabilité. Comment peut-on valider et légitimer les droits de l'homme dans leur nature et leurs fondements objectifs? Le concept de 'droits de l'homme' est-il le produit d'une histoire particulière ou estil indiscutable et universellement valable en tout temps et en tout lieu? Ses postulats sont-ils aussi universels qu'ils semblent l'être? Y a-t-il un accord général à ce propos pu peut-on formuler des griefs à l'adresse de la déclaration universelle des droits de l'homme ? Bref, quel est leur statut épistémologique? „Yacoub, Joseph. À l'épreuve des civilisations et des cultures. Repenser les Droits de l'homme. Université Catholique de Lyon. IDHL. Lyon. Octubre, 2001

17. ibid. Pág. 12-19 
expandir las libertades individuales y 2) el uso de las libertades individuales no sólo para mejorar las vidas respectivas sino también para conseguir que los mecanismos sociales sean mejores y más eficaces $^{\prime 18}$

Del anterior argumento podemos desprender el problema de la relatividad de la aplicación de los derechos en relación a los contextos sociogeográficos. El problema de los derechos reside en la aplicación real de su justicia y equidad. El derecho a la alimentación o a la vivienda se aplica de diversas maneras y depende en suma de la fuerza de demanda y exigencia que un grupo local pueda presentar. Esta fuerza se encontraría expresada en la capacidad de movilización de recursos físicos o simbólicos: la manifestación o el lobby político. Por ello la realización de los derechos significa no sólo desarrollo en términos materiales sino también aprendizajes de valores como democracia, ciudadanía o participación; tan fundamentales para garantizar los derechos en el desarrollo.

Esta noción de derechos trasciende los límites teóricos de la norma jurídica y se vincula a la necesidad individual y colectiva en tanto que, dichas necesidades, no se manifiestan como norma o regla, sino que son vividas de manera concreta en la esencia corporal de los individuos o de los colectivos. Ello porque un sujeto no siente necesidad de una norma o de una ley para satisfacer su derecho a la alimentación, por ejemplo, sino que simplemente siente hambre, frío, deseos o, en el ámbito de relación entre sujeto y colectivo, necesidad de organización para alcanzar la plena satisfacción de sus necesidades.

\section{NECESIDAD Y DESARROLLO}

El discurso de la ciencia económica se ha caracterizado por ser, entre las ciencias sociales, como aquel que presume de comprender la realidad "objetivamente", amparado en el uso de las matemáticas así como de sofisticados modelos que supuestamente dan cuenta de la manera más fiel de lo que sucede en dicha realidad.

Bajo ese supuesto, su fin como ciencia es resolver el tema de las necesidades y el bienestar de las personas a partir del uso "eficiente de los recursos" con que cuenta una sociedad, entendiendo por estos al capital, la tierra y el trabajo. Justamente, considerar la acción del hombre en el nivel de simple recurso, es desligarlo de su condición de ser humano otorgándole una connotación biopolítica bien particular. Biopolítica entendida como esa complejidad que surge de la actividad de las personas que en tanto seres vivos deben producir socialmente y ser controlada racionalmente, dice un eminente analista colombiano; pero esta categoría es vista de manera particular por la modernidad "La biopolítica es entendida como la forma en que se ha intentado racionalizar a la práctica gubernamental fenómenos propios de un conjunto de seres vivos constituidos como población y su relación con el orden social y el sistema económico" (Sarmiento 2001, 66)

En esa visión, el trabajo humano es considerado un factor más de producción, el ser humano es reducido a la categoría de recurso susceptible de ser usado eficaz y eficientemente. Es decir, el imperativo de acumular supone una reducción de la integralidad de la vida humana a una dimensión estrictamente económica, que supedita la actuación de esos seres vivos a esta lógica y se ve en la necesidad de controlarlos para garantizar dicha acumulación. La supremacía de lo económico, como fin del progreso, determinó entonces que la actividad humana de producir fuera vista en su manera más instrumentalizada y negada como una actividad proveedora de sentidos, de creatividad y de cooperación.

Al pensar la actividad productora del hombre como un recurso que debe ser eficaz para hacer "mercancías" (ser productiva), desconoce al trabajo de este como un verdadero creador no sólo de bienes para su subsistencia, sino que lo

18. Sen. Ob. Cit. Pág. 49 
despoja de la significación de formas de ser y estar de los hombres a partir del trabajo, de maneras de interrelacionarse una comunidad o una región desde sus prácticas productivas.

Hay que recordar, en esa línea de pensamiento, que buena parte de la ciencia económica ha erigido al mercado como el espacio esencial y definitivo donde las personas deben y pueden tramitar sus intereses económicos, que los llevará a realizar otras necesidades de orden cultural o social. Este reduccionismo del mercado, visto simplemente como un lugar de intercambio de mercancías, menos que como una de las varias posibilidades de encuentro de formas de ser y estar, de trámite, re-creación, de reconocimiento del otro, ha condicionado y limitado las posibilidades del desarrollo olvidando además consideraciones de tipo ético y moral.

En ese sentido, hay que recordar que las pretensiones de la economía como disciplina absolutamente científica a la manera de la física, tiene como génesis a la llamada escuela neoclásica desarrollada hacia finales del siglo XIX $y$ comienzos del XX. Con sus diversos enfoques, en general parte del supuesto de que las personas sean agentes individuales que buscan, en el mercado, la mejor manera de satisfacer sus deseos egoístas. La utilidad ${ }^{19}$ que se derive de dicha satisfacción es lo que cuenta $y$, en consecuencia, nos encontramos con un individuo cuyo interés personal es lo que prevalece, obviando su relación de interdependencia con el "otro"; este es funcional a él, no es su igual, y en consecuencia desdeña consideraciones de tipo ético y moral. Como lo explica Sen "... la utilidad de una persona representa una medida de su placer o felicidad. La idea es prestar atención al bienestar de cada persona y, en particular, concebirlo como una característica mental, a saber, el placer o la felicidad generados". (Sen 2000,80 )
Se observa, pues, una connotación bastante utilitaria del concepto de necesidad: simplemente esta es función de unos consumos que a su vez están determinados por el ingreso de las personas.

Para Sen, este enfoque se basa en las consecuencias o resultados que generan las elecciones de las personas. Elude el tema de los principios, independiente de los resultados. Hay una consideración de orden consecuencialista ${ }^{20}$ porque es un bienestar que solo valora las situaciones en función de las utilidades que generan. Aspectos que para Sen son fundamentales, como la calidad de vida, los derechos, la libertad individual, el reconocimiento, se excluyen.

En realidad, como se ha reconocido en el ámbito de producción científica de la economía y señalado por diferentes críticos, un solo enfoque de Interpretación y análisis se ha posicionado en el campo de la misma. "Entendemos por tal, el espacio de producción simbólica de conocimientos económicos y las redes de distribución (socialización). Comprende, en consecuencia, los agentes productores y las instituciones involucradas en este proceso y las relaciones que se establecen entre ellos. Se da un desarrollo relativamente rápido de internacionalización de la disciplina que toma la forma de una universalización de las prácticas y percepciones de la academia americana"21 (Misas 2004, 207)

De hecho, así lo afirma Gabriel Misas de la Universidad Nacional "La internacionalización de la economía o su "americanización" no se logró por los méritos intrínsecos de las nuevas teorías, sino en virtud de las redes construidas y desarrolladas con ese propósito" (Misas 2004, 209). Lo esencial aquí es ver cómo esta evolución de la economía tiene su raíz en el "nuevo tipo del empresario individualista" (Weber: Ética

19. De ahi se deriva el nombre de la escuela utilitarista para este tipo de análisis económico

20. Hay dos procedimientos desde los cuales se justifica o se critica una acción o una situación. "El primero de ellos el deontológico, evalúa un estado de cosas o una acción por los principios que encarna o lo inspiran... El segundo, el consecuencialista, evalúa una acción por sus consecuencias: examina como quedan las cosas después de realizarla" Félix Ovejero Mercado, Ética y Economía. Icaria, Barcelona 1994 Póg. 17

21. El subrayado es nuestro. 
protestante y el espíritu del capitalismo) que emerge luego de un largo proceso de cambios fundamentales que van desde el inicio del renacimiento, hasta la primera consolidación de la economía capitalista. "Caracterizan ahora al nuevo tipo de economía y al nuevo tipo de hombre económico, una fuerza motora, impulsiva y expansiva, ... Así, es posible que la economía monetaria y el crédito desarrollen el espíritu de empresa en grado hasta entonces desconocido (Von Martin 1932, 25)

En general, la fundamentación epistemológica de la economía está en consonancia con esos grandes cambios que ocurren con la revolución industrial y en los que, por lo menos en el surgimiento de una ciencia nueva que postula al conocimiento científico como la manera de acercarse a la verdad del mundo exterior, todo lo que no sea absolutamente verificable $y$ cuantificable $^{22}$, cae en el terreno de la especulación y en consecuencia pertenece más a los campos de disciplinas como la filosofía. En esta línea nos lo recuerda un investigador español en relación con las polémicas que al respecto ha habido: "Unos la afirmaban y sostenían que la idea de una ciencia es explicar y que queda para otros, para los políticos fundamentalmente, la de realizar evaluaciones morales" (Ovejero 1994, 143).

Entonces, paradójicamente, la economía ha venido trabajando e intentando explicar fenómenos de naturaleza eminentemente social, con fundamentos y métodos que algunas veces niegan dicha naturaleza. La crisis de las sociedades actuales en todos los órdenes, justamente empiezan a llamar la atención sobre ese vacío de consideración cultural, social, humana y ética que afecta a una ciencia social como la economía y que la instan a reconsiderar su papel con preguntas claves. Toda esa crisis de la economía lleva a pensar entonces en las alternativas posibles para superar esta situación. "De lo que se trata ahora es de saber si podemos lograr simultáneamente la eficiencia, la libertad y la justicia". Por fortuna la teoría económica de esta década está haciendo una relectura de los temas del egoísmo, el utilitarismo y la eficiencia para volver directamente a los valores morales, perspectiva en la que ciertamente se puede distinguir entre el egoísmo como un vicio moral condenable, y el interés propio cuya persecución es lícita dentro de un orden preciso no sólo jurídico, económico y sociológico sino también ético" (Bejarano 1998, 13)

Este énfasis que se ha querido dar al papel de la economía y sus implicaciones en derivar conceptos como necesidades y desarrollo es importante para entender, precisamente, qué viene pasando con dichos conceptos desde la economía y cómo podría entenderse o plantearse una nueva mirada para comprender el desarrollo humano y social.

\section{LAS PERSPECTIVAS SOBRE DESARROLLO Y NECESIDADES}

Luego de décadas de crecimiento económico en los países industrializados y algo en aquellos que no lo eran, el mundo se dio cuenta de que ese crecimiento no se traducía necesariamente en bienestar. Los niveles de pobreza y exclusión que soportaba una gran parte de la humanidad, no eran consecuentes con el ideal de progreso prometido. En la configuración del mapa mundial de posguerra, aparecían unos países avanzados y otros "subdesarrollados", por lo tanto, se trataba de que estos últimos alcanzaran los niveles de los primeros y así, la promesa del progreso sería una realidad. "El propósito era bastante ambicioso: crear las condiciones necesarias para producir en todo el mundo los rasgos característicos de las sociedades avanzadas de la época: altos niveles de industrialización y urbanización, tecnificación de la agricultura, rápido crecimiento de la producción material y los niveles de vida, y adopción generalizada de la educación y los

22. Básicamente el paradigma del positivismo que ha tenido una fuerte influencia en el pensamiento científico occidental y cuyos fundamentos, muy importantes para las ciencias exactas, han sido trasladados mecánicamente a las ciencias sociales y, en particular, a la economía. 
valores modernos" (Escobar 1996, 19)

Una visión homogeneizante desde los países más "prósperos" se impuso sobre la noción del desarrollo. Surge la "economía del desarrollo" como aquella parte de la ciencia económica que se especializa en dar el desarrollo y el progreso a estas naciones pobres. Se institucionalizan toda una serie de programas, acciones, relaciones y organizaciones para emprender la aventura del desarrollo. Una especie de cruzada llega especialmente de los (EU) y tiene al BM y al FMI como sus escuderos para emprender la batalla contra el subdesarrollo. La época inmediatamente después de la posguerra marca el inicio de esta cruzada. Estas organizaciones, programas y economistas "... desembarcaron en el tercer mundo después de la guerra, llenos de buenas intenciones y equipados con las herramientas de su profesión, a veces hasta con una agenda progresista y fortalecidos por el brillante ajuste que la mente de Keynes acababa de hacer a su ciencia" (Escobar, 114)

Es decir, hay una idea del mundo que puede ser perfecto y organizado. Los países desarrollados son la imagen de que el progreso ascendente propuesto por la modernidad es posible y es necesario volverlo un hecho. En realidad, no hay que ahondar más sobre lo que sería conveniente para las regiones más pobres, sólo se trata de desarrollarlas. Al respecto, Escobar nos cuenta como esa idea se trae a nuestros países a través de planes para el desarrollo y como la imagen de quienes venían, como el caso de Colombia con el famoso plan Currie, era de que aquí todo estaba desordenado y se trataba de ordenar y organizar, es decir "... la necesidad de ordenar el mundo. Si lo único que Currie pudo percibir a su llegada a Colombia fueron problemas, oscuridad y caos, era porque Colombia se negaba a presentarse como imagen legible para él. El desarrollo dependía de construir al mundo como imagen, para que el 'todo' pueda ser captado ordenadamente, como parte de una 'estructura' o 'sistema'. Para el economista la imagen es provista por la teoría económica" (Escobar 1996, 115)

Esta visión desarrollista se impuso al margen de la consideración de las particularidades de cada región, entonces la naturaleza de las necesidades siguió atada al concepto de crecimiento en donde el bienestar se logra a través de una mayor capacidad de consumo. Estas posturas tienen gran fuerza y son las únicas que detentan la verdad sobre la capacidad del desarrollo.

\section{LAS NECESIDADES DESDE LA PROPUESTA DEL DESARROLLO A ESCALA HUMANA}

Hay que considerar en primer lugar que los autores de este enfoque parten de la profunda crisis social, económica, ambiental, política y económica en que se ven inmersas las economías latinoamericanas en particular, aunque no exclusivamente, desde la aplicación de las políticas de choque impuestas por organismos internacionales como el FMl y el BM, enmarcadas en procesos de globalización ${ }^{23}$ económica.

Como ellos mismos afirman "En lo económico, el sistema de dominación sufre actualmente cambios profundos, donde inciden de manera sustancial la mundialización de la economía, el auge del capital financiero, con su enorme poder concentrador, la crisis del Estado de Bienestar, la creciente participación del complejo militar en la vida económica de los países, y los múltiples efectos de las sucesivas oleadas tecnológicas en los patrones de producción y consumo" (Max-Neef y otros: 1986, $15)$.

En segundo lugar, la génesis y desarrollo del concepto, se enmarca en una búsqueda de miradas y alternativas diferentes a enfoques manifiestos por una visión reduccionista de la economía, que pretende ver el desarrollo como una simple consecuencia del crecimiento económico.

23. Hay que aclarar la distinción de términos como globalización y mundialización; para algunos autores como Renato Ortiz, la globalización se refiere más a los procesos económicos en estricto sentido, mientras que la mundialización estaría refiriéndose a los grandes cambios culturales que provoca esa globalización y de ahí que hable de la mundialización de la cultura. Una cultura que vende productos universales a una gran familia mundial que consume los mismos productos en cualquier lugar del mundo. 
En esa perspectiva, el trabajo de estos autores pretende comprender el problema de las necesidades bajo un enfoque integral y necesariamente transdisciplinario en los que el concepto de necesidades humanas fundamentales constituye el centro de pensamiento y acción para esta propuesta.

Se encuentra aquí ya un viraje fundamental para asumir el "desarrollo a escala humana" en tanto que se reconoce una integralidad de dimensiones y elementos; no es sólo la satisfacción de necesidades humanas fundamentales, sino de generar autodependencia, el reconocimiento de la articulación de los seres humanos con la naturaleza y la tecnología, así como de los procesos globales con los locales, la planificación con la autonomía, lo personal con lo social y la sociedad civil con el Estado. Es decir, rompe con un paradigma de individualidad asumido por occidente, en donde lo que cuenta son los deseos de un individuo ajeno a su entorno y sin consideración por aspectos tales como lo ambiental y la democracia. No hay, en esa medida, un proyecto colectivo en donde el concepto de necesidad queda restringido a la simple posibilidad de consumo.

En este trabajo, el concepto de necesidad cambia de perspectiva al criticar la idea comúnmente aceptada de que las necesidades humanas tienden a ser infinitas y que están constantemente cambiando, que son diferentes en cada cultura y varían en cada periodo histórico. Por el contrario, plantean que las necesidades son finitas, pocas y clasificables, que son las mismas en todas las culturas y periodos históricos y lo que cambia a través del tiempo y las culturas es la manera de satisfacer esas necesidades. A esa manera que cada sociedad tiene de satisfacer las necesidades las llaman satisfactores

Para hacer un acercamiento al concepto de necesidad, realizan una clasificación bajo dos categorías; de una parte categorías existenciales (ser, tener, hacer y estar) y, de la otra, las axiológicas (que incluye necesidades tales como subsistencia, protección, afecto, entendimiento, participación, ocio, creación, identidad y libertad). Las personas, sostienen, son seres de necesidades múltiples e interdependientes, ya que ellas se interrelacionan e interactúan y por eso argumentan que "Un satisfactor puede contribuir simultáneamente a la satisfacción de diversas necesidades o, a la inversa, una necesidad puede requerir de diversos satisfactores para ser satisfecha" ${ }^{\prime 24}$

Como puede observarse, hay una clara posición crítica frente a una noción aprehendida en la que la necesidad es vista como una función de consumo equivalente al deseo de "tener" cosas, apropiar o atesorar objetos materiales y simbólicos. Supondría ello que la satisfacción estaría dada por la capacidad de consumir, de tener utilidad como expresión de un deseo satisfecho, ajeno a la integralidad del ser humano, sino más bien referenciado, como dice Amartya Sen, a la idea de placer ${ }^{25}$. Un individuo, sólo, ajeno a su entorno ambiental, social, que tiene utilidades entre más consumo presente.

Así, también distinguen el concepto de bienes económicos entendidos como objetos y artefactos que permiten incrementar o mermar la eficiencia de un satisfactor. La idea sugiere que lo determinante, para que haya satisfacción de necesidades fundamentales $y$, por tanto, desarrollo, son la elección de los satisfactores adecuados, por encima de los bienes económicos. Pero, como afirman "los bienes se han convertido en elementos determinantes dentro de la civilización industrial. La forma como se ha organizado la producción y apropiación de bienes económicos a lo largo del capitalismo industrial ha condicionado de manera abrumadora el tipo de satisfactores dominantes"26. Es decir, la prelación al bien en sí mismo, al consumo, obviando el satisfactor y en consecuencia la satisfacción de la necesidad.

24. Ibid, Pág. 30

25. Sen, Amartya. "Desarrollo y Libertad" Ed. Planeta, Barcelona 2000, Pág. 80

26. Max Neef, otros O.C. Pág. 38. 
Desde la mirada de estos autores, una sociedad ascética tendría las mismas necesidades que una consumista, pero la diferencia estaría en la elección de los satisfactores para satisfacer esas necesidades. Esto nos remite al tema del cambio en las prácticas culturales de consumo. En resumen, nunca consumir más significa satisfacer las necesidades fundamentales de la persona, visto como ser integral y no como máquina de consumo.

Otra conclusión a la que llegan, revela una nueva concepción de pobreza en la que esta se desliga de la visión economicista que la define como falta de ingresos. Por el contrario, la pobreza o pobrezas sería cualquier necesidad humana no satisfecha adecuadamente.

Profundizando en el tema de la necesidad, esta se ve así en una doble condición: como carencia y como potencialidad. Necesidad no sólo refiere a subsistencia, sino a la potencia de los seres humanos. No restringe el concepto a "la falta de algo", para situarlo en el plano de la potencia porque motivan y movilizan a las personas. Es decir, se comprende la necesidad como un proceso incesante y por eso consideran que hay que "vivirlas y realizarlas de manera continua y renovada" ${ }^{\prime 27}$.

Por último, se encuentra una crítica clara a los enfoques de la economía de mercado. La economía propone el concepto de preferencias del consumidor cuyo fundamento, en lugar de concebir a un ser humano con necesidades y potencialmente creador a partir de las mismas, lo piensa como un receptor de mercancías (bienes económicos) que satisface deseos. "las preferencias se definen en el ámbito de lo subjetivo particular, son competencia de cada persona ${ }^{\prime 28}$, de ahí, pensamos, la base individualista de esta concepción. "Lo universal - subjetivo", por el contrario, remite al reconocimiento del ser humano en sintonía con los otros, que piensan en la trascendencia y en donde lo central es la necesidad y los satisfactores conducentes a la actualización de esas necesidades.

De otro lado, en un trabajo reciente del profesor Antonio Elizalde, la necesidad es asociada a la naturaleza humana la cual está constituida por biología y psicología. Esta naturaleza humana ha cambiado poco en la historia, de alli que se reconozca lo finito de las necesidades.

La base particularmente humana de esta propuesta, permite realizar una crítica a las visiones dominantes, en especial de aquellas que parten de la cultura occidental. La necesidad de una nueva epistemología que rompa el paradigma positivista, que hable de la existencia de una sola realidad objetiva por lo que se trataría de conocerla. En la propuesta, por el contrario, rescata la dimensión subjetiva de la realidad, la manera como es posible que esta no sea única y pueda ser vista y percibida de diferentes formas. El centro de esta mirada es ver el problema desde las subjetividades y no sólo desde lo racional. "... tratamos a un tema que es del ámbito de los deseos que guían el hacer, como si fuese un tema racional en el que sería la razón lo que guiaría la conducta" ${ }^{\prime 29}$

De ahí que proponga una categoría, el emocionar, como diferente al razonar. El problema de las necesidades no podría caer exclusivamente en el ámbito de la razón y por esta razón formula un cambio de paradigma que no está en la economía o la política, sino "... en el plano de nuestras creencias, son ellas las que determinarán el mundo que habitemos ${ }^{\prime \prime 30}$. De ahí que el concepto de necesidad se equipare al de deseo y en tanto este es infinito, las necesidades lo serían, para lo cual el sistema económico existiría (o existe) para colmar todas esa necesidades infinitas y "por tal razón está funcionalizado hacia el crecimiento.... Casi toda la reflexión económica está organizada en torno al crecimiento" $^{\text {"31 }}$

29. Elizalde, Antonio "Desarrollo humano y éfica para la sustentabilidad" Universidad Bolivariana PNUMA, Chile 2003, Pág.

30. Ibid, Póg. 30

31. Ibid, Póg. 32 
Por el contrario, en este enfoque se relaciona la necesidad humana con la naturaleza humana, biología, psicología, es decir, habla de un ámbito fisio neuro psicológico en el que está la vida humana y esta, al decir de Elizalde, ha cambiado muy poco en la historia de la humanidad. Ello significa que las necesidades son las mismas $y$, como se ha mencionado en el enfoque de desarrollo a escala humana, surge el concepto de satisfactor, el cual da cuenta de la "dimensión aparentemente cambiante de la necesidad ${ }^{\prime \prime 2}$ pero lo que quiere expresar es que lo que cambia de cultura en cultura y a través del tiempo, es la forma como se satisfacen esas necesidades.

Este intento por desligar el concepto de "necesidad", del criterio estrecho de la producción de mercancías y del consumismo, anulando a su vez el imperativo de que hay que crecer aún a costa de la utilización y agotamiento de los recursos naturales, pone en el centro de la cuestión que las necesidades de los hombres no puede tener como fundamento de realización exclusivo el ámbito económico. En realidad, este es tan solo un medio, por cuanto lo humano se realiza plenamente desde otros ámbitos o dimensiones.

La noción anterior llama así la atención para que las propuestas de desarrollo cambien el estatuto ontológico desde el que tradicionalmente se han planteado; no se trata de producir bienes para una supuesta satisfacción de necesidades, se trata más bien de la creación de nuevos órdenes sociales más dignos, en donde lo económico simplemente sea una de las maneras en el que culturalmente los hombres crean ciertos tipos de relaciones de producción e intercambio como una parte de su "vivir".

BREVE GÉNESIS HISTÓRICA DE LOS PARADIGMAS ECONÓMICOS SOBRE EL DESARROLLO

No es la intención hacer aquí un recuento exhaustivo sobre este tema, pues no es su fin. Se pretende señalar del modo más sencillo cómo casi todas las teorías económicas han querido impactar en el tema del desarrollo y han puesto su impronta en el mismo.

Desde sus primeros teóricos se pretendió dar, implícita o explícitamente, una respuesta al bienestar de sociedades, con las limitaciones propias de esta ciencia "racional". Las teorías clásicas no hablan en sí mismas del desarrollo porque al considerar como esencial el crecimiento económico, sientan las bases teóricas e ideológicas para asumir que este en sí mismo es desarrollo. Smith, Ricardo y Malthus son los teóricos que inician la construcción del edificio teórico sobre el que se definirá hasta ahora una concepción hegemónica sobre estos asuntos.

El fundamento principal es encontrar las razones del crecimiento económico y dotar de una teoría al nuevo sistema de producción social que emerge luego del feudalismo. Más allá de sus enfoques, estas teorías siempre ven la consecución de la riqueza como el fin que proveerá a una sociedad de bienestar. Sobresale, de todos modos, aspectos de control político que les subyacen y en donde además, se da por cierto que es la acción individual la que garantizará el bienestar del colectivo. Los tres enfoques teóricos, como se ha mencionado, dan a la economía un supuesto valor científico al generar cada vez más un análisis basado en la existencia de leyes que rigen el sistema, al modo como sucede en la naturaleza, de donde deriva sus niveles de abstracción, formalización y cuantificación que tomará posesión de esta ciencia en forma más contundente con la teoría neoclásica.

Marx, de otra parte, comprende la naturaleza del nuevo sistema como histórica, la cual tiene como fundamento el deseo de acumular y la contradicción permanente e inevitable entre dos clase sociales, la una sojuzgada por la otra. Necesariamente implica que no hay desarrollo y que este vendrá como producto del surgimiento de un nuevo orden social. Un aporte esencial es el

32. Ibid Pág. 32 
que entiende el bienestar de las personas como no dado por el simple hecho de la acumulación y el crecimiento, pues estos dan beneficios diferentes según la posición en el sistema. El progreso en Marx, en consecuencia, no es posible porque el excedente en realidad es plusvalía, valor que se le quita al trabajador.

La crítica que desde lo histórico le plantea a la economía de mercado como no dada, así como al supuesto carácter individual de la apropiación del conocimiento, ponen la cuestión de las necesidades en otra perspectiva. Se vislumbra que los hombres no pueden ser sujetos de la imposición de consumir mercancías pues al analizar el valor de cambio como noción que "iguala" el valor de estas en el mercado para intercambiarlas, les arranca su naturaleza de sentido, el para qué sirven y qué beneficio realmente le brinda a quién la consume. De ahí que uno de sus análisis fundamentales haya sido el del fetichismo de las mercancías y la manera en que éstas se convierten en la esencia del sistema; podríamos decir, se vive para consumir, en lugar de consumir (y lo que sea esencial) para vivir bien.

Es claro, entonces, que avanzó en dar los cimientos para posteriores teorías que irían más allá de lo económico, para adentrase en aspectos sociales y culturales.

Los tres pensadores mencionados tuvieron en el centro del análisis las categorías de producción y trabajo que marcan a nivel epistemológico la evolución de la misma, pero lo más destacados, fue la construcción cultural que de ella fuimos haciendo. Nada podía ser si no era pensado a través de estas nociones que, como diría Morin, son ideas hechas por los hombres que al final van tomando posesión de nosotros hasta el punto de que las damos como dadas, inamovibles $e$ incuestionables.

Todas las teorías que siguen, desde los neoclásicos con su énfasis en la utilidad y el papel del individuo racional que busca maximizar ganancias y que suponen una distribución óptima de los recursos y generación de crecimiento económico, pasando por Schumpeter con una idea que distinguía el papel de la técnica y la innovación como motor del desarrollo y llegando a Keynes con la propuesta de un Estado interventor y su cuestionamiento, importante por lo demás, de que el mercado no maximiza el bienestar de las personas, denotan simplemente como el desarrollo y las necesidades, en tanto categorías de análisis, simplemente son subordinados al problema de la producción y el crecimiento.

Hubo intentos más críticos desde las teorías estructuralistas en América Latina que intentan romper el vínculo con el norte pero que al final repiten el modelo: el desarrollo se logra es con la industrialización, en este caso, con la propia capacidad de los países no desarrollados para crear un aparato productivo capaz de generar crecimiento y en donde la tecnología es el motor del desarrollo. La teoría de la dependencia, de otro lado, nos habla de las condiciones de existencia y funcionamiento del sistema económico y del sistema político, las vinculaciones entre ambos, tanto en el plano interno como externo de los países y como se constituye en la forma como históricamente fueron vinculadas las economías de los países atrasados industrialmente al mercado mundial. Es un intento por pensar la situación de los países latinoamericanos, desde un enfoque histórico y teniendo en cuenta aspectos políticos, sociales y culturales.

Finalmente, el economista Myrdall, comprende que además de lograr la industrialización para generar riqueza, los países deben generar condiciones mínimas para que las personas tengan un mínimo de equidad $y$ redistribución porque reconoce que mientras haya pobreza y desigualdad, estas serán un obstáculo para el crecimiento económico. De aquí surgen los primeros intentos para la posterior aparición del concepto de necesidades básicas. Sin embargo, el verdadero problema sigue invertido: las necesidades humanas en función del crecimiento y no lo contrario, es decir, que el sistema de necesidades determine como debería funcionar el sistema material de producción, distribución y consumo. Lo humano aún en relación de sometimiento con el crecimiento.

Todas estas teorías, con sus diferencias, no dicen nada de las personas y grupos humanos en 
cuanto a qué es lo que desean y cómo. Sus verdaderas necesidades, gradualmente se ven afectadas por un discurso y una práctica sobre la importancia del consumo de mercancías como la plena y verdadera realización humana. El supuesto implícito es el mismo: "vamos a crecer, eso nos desarrollará $y$, como efecto, tendremos el bienestar".

Se ha venido insistiendo en estas líneas el papel de la economía como ciencia que moldea nuestros conceptos de desarrollo y necesidades a un nivel que ha permeado todo el imaginario social frente a los mismos. De ahí que "Sencillamente, la gente moderna llegó a ver la vida en general a través de la lente de la producción. Muchos aspectos de la vida se volvieron cada vez más economizados, incluyendo la biología humana, el mundo natural no humano, las relaciones entre las personas, y las relaciones entre la gente y la naturaleza" (Escobar, 123)

\section{LAS CRÍTICAS AL DESARROLLO}

La economía se considera el paradigma de la racionalidad, porque ella trata de lo que produce la sociedad y se centra en las cantidades, todo es mensurable y esta actividad se hace de la mejor manera posible (Castoriadis: 1979, 196). Para este autor, el desarrollo que propone occidente, sólo quiere significar la capacidad de crecer sin fin. Es ideología y, a un nivel más profundo, significaciones imaginarias sociales. Consustancial a esa idea del desarrollo, existen unos postulados (teóricos y prácticos) que la soportan (Castoriadis: 1989, 195):

- La omnipotencia virtual de la técnica

- La ilusión relativa al conocimiento científico

- La racionalidad de los mecanismos económicos
Diversos lemas que sustentan la idea de que el hombre y la sociedad están "naturalmente" predestinados al crecimiento y al progreso. Tienen cabida aquí, conceptos e ideas tales como el homus economicus, la mano invisible, liberalismo y virtudes de libre concurrencia. ${ }^{33}$

Entonces, la "crisis del desarrollo" es la "crisis de esos postulados" y de que las significaciones imaginarias que sustentan esas ideas se aceptan cada vez menos. Hay una continuidad y profundidad del pensamiento marxista, toda vez que advierte que términos como racionalidad, desarrollo, economía, son indistintamente utilizados por el pensamiento occidental, sin comprender los verdaderos alcances de los mismos.

En esa línea, Morin también desenmascara este concepto que hizo su aparición en el mundo desde los años 50. Al respecto dice "Se ha impuesto como una noción maestra, a la vez evidente, empírica (mensurable por los índices de crecimiento de la producción industrial y de la nivelación del nivel de vida), rica (significando por si misma a la vez crecimiento, expansión, progreso de la sociedad y del individuo). Pero apenas se ha visto que esta noción era también oscura, incierta, mitológica, pobre" (Morin, 223)

Bajo la lógica racional de occidente, propuesta por la modernidad, el progreso es la razón del ser humano y la sociedad. Se trata de que pasamos sucesivamente de etapas de subdesarrollo a otras cada vez más modernas y desarrolladas. El mundo se representa en una escala ascendente que se debe remontar y el desarrollo es, así, evolución de peores a mejores estados. Pero la connotación social, económica y política de la vida de los hombres no se puede proponer en forma lineal, pues desconoce el inevitable caos de estos procesos que pueden ser algunas veces controlados por los hombres, pero que al mismo tiempo pueden producir efectos inesperados.

La riqueza de la creación se pierde en las

33. También son consustanciales a esta idea, los conceptos de ingeniería humana e ingeniería social: organización y planificación burocráticas como soluciones universales aplicables a todo problema. Castoriadis O.C. Pág. 195 
razones de una racionalidad que sólo apunta a un objetivo preciso (el progreso) y del cual sólo se trata de ir a buscarlo. "En la base de la idea maestra de desarrollo estaba, pues, el gran paradigma del humanismo occidental; el desarrollo socioeconómico sostenido por el desarrollo científico técnico, asegura por sí mismo expansión y progreso de las virtualidades humanas, de las libertades y poderes del hombre" (Morin; 1980: 224).

Entonces, se considera el "desarrollo" separado de la complejidad del mundo. Hay un desconocimiento total de las diversas culturas que habitan el planeta, de la forma en que ellas asumen su vida y sus interacciones de maneras distintas a la lógica occidental. Tampoco se evidencia el papel del hombre en relación con la naturaleza, pues esta es vista sólo como un recurso a potenciar y explotar, es decir, el hombre se eleva sobre ella y no reconoce que tan sólo es una parte de la misma. "Se descubre aquí que en la raíz misma de la noción de desarrollo lo pobre es precisamente lo que parece más rico: la idea del hombre y la idea de la sociedad" (Morin;1980:226).

De un modo terriblemente sistemático, lo que se creó fue un sistema perverso para garantizar acumulación, expansión y reproducción del capital. En virtud de ello, se hace indispensable "diseñar" mecanismos de control sobre las personas y nace como realidad el proyecto de la modernidad y su "razón instrumental" que controlan al cuerpo y la mente humana para convertir finalmente a la persona en instrumento y en el cual el poder, al decir de Sarmiento, dirige la educación de este cuerpo y esta mente, hasta llegar a controlar las condiciones socio demográficas como elementos esenciales en la constitución del capitalismo. "El poder dirige la educación del cuerpo y la mente, el aumento de sus aptitudes, el arrancamiento de sus fuerzas, el crecimiento paralelo de su utilidad y docilidad, su integración en sistemas de control eficaces y económicos" (Sarmiento 2001, 66)

En la vida actual, ese poder es para controlar toda la existencia humana; los grandes cambios tecnológicos y la necesidad de acumular capital, consideran al ser como cliente consumidor reproductor de mercancías, asignador de valores económicos, por encima de cualquier otro. Biopolítica, entonces, como vida controlada social e individualmente en función del capital. Una noción de libertad, de creación no existe aquí.

Las "necesidades y deseos" de los hombres son así reducidos, a partir de esa economización de la vida cotidiana, al consumo de mercancías que supuestamente le brindaran bienestar. Pero su esencia como ser humano se pierde en esa fetichización de la mercancía por lo que el desarrollo definitivamente queda atrapado en los supuestos de la economía neoclásica: competencia y racionalidad perfecta. Estos supuestos, por lo demás, actuarían en el mejor de los escenarios posibles, el mercado. De ahí que la noción de trabajo es desvirtuada, este ya no es la acción creadora de los hombres que le permite además lograr comunión con los otros. Es una categoría que da valor y más adelante ni siquiera aparece como el generador de este valor, sino que utilidad entendida como "calidad abstracta por la cual un objeto sirve nuestros propósitos y adquiere rango de bien ${ }^{\prime \prime 4}$. El trabajo humano, se reduce a un problema de utilidad para "satisfacer nuestros deseos al máximo con el mínimo de esfuerzo" ${ }^{\prime \prime 35}$

No es reprochable que las personas quieran satisfacer deseos, pero lo que subyace a estas ideas es el individualismo que propone, una noción de competencia absoluta y la base propuesta de que el bienestar es un problema de consumo. La integralidad y multidimensionalidad del desarrollo se disuelve en unos postulados que implican que las necesidades esenciales son propuestas por el mercado, no por los reales deseos de las personas.

Las cosas, los objetos económicos, la competencia se posesionan en las necesidades profundas de los hombres. Escobar cita a Foucault "Las personas trabajan y comercian

34. Postulado de los principales economistas de la escuela neoclásica. Citado por Escobar Pág. 130.

35. Ibid 130 
porque experimentan necesidades y deseos, pero sobre todo porque están sometidas al tiempo, a la lucha, y en última instancia, a la muerte" ${ }^{\prime 36}$

Frente a esta consideración, la organización capitalista, entendida como la máxima forma de desarrollo de las fuerzas productivas que conoce la historia, supone el desarrollo del mundo material que a su vez, determina un modo de vida de los individuos. Las ideas de estos, su conciencia, son producto de la forma como producen. "Lo que los individuos son depende, por tanto, de las condiciones materiales de su producción" (Marx: 16, s.f). Esta concepción, bastante compleja y estudiada en varios escritos por Marx, define la manera como, no sólo se reproduce el capital, sino la misma ideología que sustenta las relaciones de producción, bajo las cuales ella misma se reproduce.

En las tesis sobre Feuerbach, queda claro entonces que "lo humano y su esencia" surgen a partir de las relaciones sociales que se dan entre los individuos, el pensamiento humano constituye un problema práctico, pues se resuelve no meramente en lo teórico, sino en la práctica, expresión de un producto social. (Socialmente construido).

La premisa se resume así: los hombres al producir sus medios de vida, producen su propia vida material que a su vez lleva a un modo de vida. Bajo esas circunstancias es determinante en Marx, estudiar las condiciones en que los hombres producen, pues esta explica su manera de ser y estar en el mundo.

Sin embargo, Castoriadis plantea que la Psique, la imaginación radical del ser humano, no se puede reducir a unos comportamientos reflejos de lo social, sino que desde aquella hay pistas para entender la construcción de lo social humano. La psique construye su mundo independiente y a la vez en relación con el mundo social y desde aquí deriva su teoría central de la imaginación radical, no condicionada siempre por lo social y desde donde podría entenderse el desarrollo de las sociedades y los individuos.
Habla así, de la socialización de la psique como interiorización de las significaciones imaginarias sociales que también son construidas por la psique. Lo anterior supone que la construcción de la necesidad ha sido construida (Castoriadis; 1998)

En todo caso, ya se ha mencionado, las cosas al perder su valor de uso, su razón de ser, y convertirse en valor de cambio, cercenan la esencialidad de las necesidades. Apostamos por la cantidad, por el valor de cambio, el producto total de una sociedad, cuanto produce, es lo que cuenta, no lo que produce. "Las bombas $\mathrm{H}$ se incluyen en el producto neto, pues el economista 'no se ocupa de los valores de uso'" (Castoriadis; 1979:197).

Aquello que no se reflexionó es que cada sociedad o, en términos que aludan al espacio, cada comunidad, localidad, región o país tenían su propia historia, su propia dinámica. La pregunta żquién y cómo define cuál debe ser y cómo debe expresarse el desarrollo? no es más que preguntarse por la imagen que cada una de estas tiene, desea o realiza como escenario de futuro. La creación de nuevos órdenes sociales, entonces, no puede pasar por un dictamen externo a quienes lo desean y procuran hacer realidad. No se trata de aislarse del contexto, porque eso sería negar las necesarias e ineludibles interconexiones y relaciones que existen, sino de evitar las imposiciones sin consultar su propia historia. Debe germinar de aquí consideraciones de tipo ético y responsabilidad social, es decir, una forma nueva de la biopolítica que Sarmiento propone partiendo del pensamiento de Toni Negri: "Con Negri el concepto de biopolítica adquiere una forma positiva, entendido como emancipación, autogestión y politización de lo social" (Sarmiento 2001, 68).

\section{POSIBLES ALTERNATIVAS}

Bajo esta perspectiva el desarrollo se refiere tanto a los seres humanos, al medio ambiente, a

36. Ibid. Pág. 129 
las relaciones e interacciones entre las personas y por ello hablamos de un problema de integralidad. Las personas no son tan solo biología y producción de vida material: son también historia, cultura, sociedad, producción y reproducción simbólica de deseos, aspiraciones, valores. Significa la manera como habitan un territorio y se relacionan con él. Este hecho debe proveer premisas para entender cómo en la vida urbana por ejemplo - las pequeñas comunidades producen $y$ se reproducen material y espiritualmente $^{37}$ desde otras propuestas. Así que si es un problema de integralidad, hablamos de una naturaleza compleja del desarrollo, porque debe comprender diversas conexiones espaciales, temporales, culturales ${ }^{38}$ y de ahí que comporte diversas dimensiones.

Vida, trabajo y creación constituyen entonces las categorías o conceptos a partir de los cuales se expone una nueva y contundente manera de enfrentar el dilema de la existencia de los hombres individual y colectivamente. Cuando Sarmiento nos plantea la mirada sobre la vida desde un horizonte más amplio y profundo, es porque a la "vida humana" se le asigna una resignificación como potencia creadora y reflexiva, sobre la base de que en la sociedad las personas establecen relaciones culturales, sociales, económicas y afectivas que los lleva a que su vida sea pensada también como un proyecto individual y social. A esto lo llama Biopolítica.

De manera complementaria, los autores del "desarrollo a Escala Humana" manifiestan que el espacio para comprender y desplegar un nuevo concepto de necesidades parte de reconocer lo que ellos denominan "una democracia de la cotidianidad" que rescata la dimensión "molecular de lo social" (micro organizaciones, espacios locales), lo que supone un nuevo horizonte para pensar el desarrollo, ya no como un modelo igual para todos, sino de acuerdo a especificidades de las comunidades o de las sociedades locales. Por eso afirman "Ello significa modificar sustancialmente las visiones sobre estrategias de desarrollo, en el sentido de entender por ejemplo, que ningún nuevo orden económico internacional podrá ser significativo si no está sustentado en la reformulación estructural de una densa red de nuevos ordenes económicos locales" ${ }^{\prime 39}$

Al plantearse un Desarrollo a Escala Humana orientado a satisfacer las necesidades humanas, supone asumir una nueva concepción y enfoque de estas necesidades. Al reconocer que desarrollo y necesidades son elementos constitutivos de una sola realidad, parten de un postulado general: el desarrollo se refiere a las personas y no a los objetos._Por eso plantean que "el mejor proceso de desarrollo será aquel que permita elevar más la calidad de vida de las personas ${ }^{\prime \prime 40}$

Obviamente que no podría dejar de considerarse la propuesta de Sen, quien plantea el tema de las oportunidades para potenciar las capacidades de las personas y escoger, de este modo, la vida que quieren vivir. Existen, entonces, planteamientos alternativos a la visión comúnmente aceptada frente al desarrollo. Lo económico es sólo un medio, inserto dentro de un sistema más complejo que ve al ser humano no como consumidor, sino como persona creadora de otros órdenes sociales.

La dimensión económica la entendemos entonces como una de las formas de expresión de las personas, produce bienes materiales, sustenta la vida material, pero crea profundos sentidos de estar entre los hombres. "la producción de riqueza está asegurada por una comunidad biopolítica, esto es, el trabajo de quienes tiene un empleo... de todos los que contribuyen a la producción de la afectividad, de la sensibilidad, de los modos de semiotización de la subjetividad y

37. Lo espiritual entendido en el desarrollo de otras formas de relacionamiento con el mundo material que ofrece la sociedad de consumo. Las tribus urbonos (Maffesoli) como generadoras y autoproductoras de nuevos sentidos para la vida, al margen o a pesar del sistema capitalista, aunque terminen absorbidas por este o queden en el umbral de lo desconocido.

38. Por eso el desarrollo connota dimensiones espirituales y maleriales, es medio y fin, es tanto fenómeno como proceso. (Apuntes de clase del curso Dimensiones del Desarrollo, CIDER Uniandes)

39. Max-Neef. M, Elizalde. A, Hopenhayn. M. "Desarrollo a escala humana Una opción para el futuro" Cepaur, Suecia 1986 , Pág. 27

40. Ibíd, Pág. 29 
al reencantamiento de la naturaleza" (Sarmiento 2001, 68).

Por ello, se propone una biopolítica que libera y da sentido a la existencia de las personas porque el hombre ya no es masa, ni mero individuo, es "subjetividad libertaria", vale decir, reconocimiento de la vida para vivir, reconocimiento propio y del otro, no como algo ajeno, sino diferente y a la vez compañía para construcción de formas societales libres de toda opresión. Entonces, el trabajo y la creación son los fundamentos para la resignificación de la vida, expresiones de la creación, capacidades o, como diría Castoriadis, la imaginación radical del hombre, en tanto coloca a este con la capacidad de imaginar y constituir nuevas formas de vida y relacionamiento, no impuestas, sino escogidas. Si los sujetos son constituidos, también son constituyentes.

\section{BIBLIOGRAFÍA}

Attali. J, Castoriadis. C, Domenach. ¡, Morin, E y otros. El mito del desarrollo. Editorial kairos, Barcelona 1980

Beauvoir, Simone de. Pour une morale de l'ambiguîté. Folio essais. Ed. Gallimard, Paris. 1947.

Benjamín Walter. Para una crítica de la violencia y otros ensayos. Iluminaciones IV Taurus Humanidades. Madrid. 1991

Boisser S. El vuelo de una cometa, Una metáfora para una teoría del desarrollo territorial.

Bourdieu, Pierre. La distinción. Criterios y bases sociales del gusto. Traducción de María del Carmen Ruiz Elvira. Ed. Taurus. Madrid. 1988

Poder, Derecho y Clases

sociales. Traducción de Maria José Bernuz Beneites. Ed. Desclées. Bilbao. 2000

Cornelius Castoriades. Reflexiones sobre el desarrollo. En: El Mito del Desarrollo pp: 183. 222 Ed. Kairos, Barcelona, 1980.

Elias, Norbert. Humana Canditio. Consideraciones en torno a la evolución de la humanidad. Traducción de Pilar Gilart Gorina. Ediciones Península. Barcelona. 1988.

La sociedad de los individuos. Traducción de José Antonio Alemany. Ed.

Elizalde, Antonio "Desarrollo humano y ética para la sustentabilidad" Universidad Bolivariana PNUMA, Chile 2003

García, Canclini Nestor. Consumidores y Ciudadanos. Conflictos multiculturales de la globalización. Ed. Grijalbo. México. 1995

Culturas

hibridas. Estrategias para entrar y salir de la modernidad. Ed. Grijalbo. México. 1990 
Gino Germani. De la sociedad industrial a la sociedad tradicional: Análisis de Transición. En: Política y sociedad en una época de transición. Editorial Paídos. Buenos Aires. 1956

Heinz R. Sonntang. Estructuras y otras estructuras: El desarrollo como progreso y los actores sociales. En: Duda Certeza Crisis: la evolución de las ciencias sociales en América Latina, UNESCO. Ed. Nueva Sociedad, Caracas, 1998.

Heller, Agnes. Teoría de las necesidades en Marx. Traducción de José Francisco Ivars. Colección Historia, Ciencia, Sociedad. Editores Península. Barcelona. 1978.

Biopolítica: Modernidad y la liberación del Cuerpo. Traducción de José Manuel Álvarez Florez. Ediciones Península. Madrid. 1995.

Hobbes Thomas. Leviatán. Grandes Obras del Pensamiento. Ed. Alianza.

IDCT. Observatorio de la cultura urbana. Consumo Cultural en Bogotá. Experiencias Vitales y Estéticas. Actuar, Sentir y Pensar/Observatorio de Cultura Urbana. Colección Cuadernos de investigación. 1998

Marx, Carlos. Manuscritos de Economía y Filosofía. Ed. Alianza, Madrid. 1969

Completas, Tomo 1. 1979.

Ideología Alemana. Obras

Max-Neef, Manfred. Economía Descalza, señales desde el mundo invisible. Traducción de Estela Lorca. Editorial Nordan, Escolmo. 1986.

Elizalde. A, Hopenhayn. M Desarrollo a Escala Humana, una opción para el futuro. Editorial Uppsala: Cepaur, Fundación Dag Hammarskjold. 1999

Morin Edgar. El desarrollo de la crisis del desarrollo. En: El Mito del Desarrollo pp: 223-256 Ed. Kairos, Barcelona, 1980.
Ovejero, Félix Mercado, Ética y Economía. Ed. Icaria, Barcelona 1994

Sen, Amartya. Desarrollo y Libertad. Editorial Planeta. Bogotá. 2000

Yacoub, Joseph. À l'épreuve des Civilisations et des Cultures. Repenser les Droits de l'homme. Université Catholique de Lyon. IDHL. Lyon, Francia. Octubre, 2001 